\title{
The Moral Duty to Buy Health Insurance
}

Tina Rulli, PhD

Ezekiel J. Emanuel, MD, PhD

David Wendler, PhD

T He 2010 Patient Protection ANd AfFordable CARE Act (ACA) was designed to increase health insurance coverage in the United States. Its most controversial feature is the requirement that US residents purchase health insurance or pay a financial penalty. Although debate focuses on the constitutionality of this individual mandate, the central concern is a moral matter-is it morally appropriate to require individuals to purchase health insurance?

Proponents argue that a mandate could lower insurance premiums for everyone by pooling individuals with varying health risks. Opponents respond that requiring people to contribute to the collective good is inconsistent with respect for individual liberty. Appeal to the collective good could justify requiring individuals to buy gym memberships or eat broccoli. ${ }^{1}$

Rather than appeal to the collective good, this Viewpoint argues for a duty to buy health insurance based on the moral duty individuals have to reduce certain burdens they pose on others. Because physicians and hospitals have a duty to rescue the uninsured by providing acute and emergency care, individuals have a corresponding duty to purchase insurance to cover the costs of this care. Requiring individuals to meet this obligation is consistent with respect for individual liberty and does not imply that they must buy gym memberships or eat broccoli.

\section{The Duty to Rescue}

Individuals have a moral duty to rescue - a duty to provide aid to others in urgent need at least when doing so involves minimal risk and burden. Certain professionals, including police, firefighters, and physicians, have a duty to rescue even when the burdens are more than minimal. This duty is embodied in the Emergency Medical Treatment and Active Labor Act, which legally requires hospitals to provide emergency care to people regardless of insurance status. Provision of care to the uninsured is estimated to cost tens of billions of dollars each year. ${ }^{2}$

The duty to rescue can generate a corresponding duty on the part of potential rescuees to reduce the burdens of res- cue. In 2011, an 8.9-magnitude earthquake in Japan generated a large tsunami. Surfers in California were warned to stay out of dangerous waters to protect themselves and also to protect other individuals who would have to rescue them. Because others have a duty to rescue, these surfers had a moral duty to reduce the chances that they would need to be rescued under treacherous conditions. This example suggests that potential rescuees can be required to take rescue precautions when 3 conditions are satisfied: (1) the chance of requiring rescue is high; (2) the burdens of providing rescue are substantial; and (3) the costs and burdens of the precautions are not excessive. The situation of the uninsured meets these criteria.

\section{A Duty to Buy Health Insurance}

Chance of Needing Care. Many individuals forgo health insurance assuming they will not need medical care. However, everyone is at substantial risk of needing medical careeven young adults. ${ }^{3}$ Fifteen percent of 18- to 29-year-olds have asthma, arthritis, cancer, diabetes, heart disease, or hypertension. ${ }^{3}$ More than half of these individuals are overweight or obese. ${ }^{3}$ In 2007, there were 2.6 million live births among women aged 18 to 29 years. ${ }^{3}$ One-fourth of all human immunodeficiency virus/AIDS diagnoses occurred in 20- to 29-year-olds. ${ }^{3}$ Almost $24 \%$ of 18 - to 29 -year-olds received treatment in an emergency department during the past year. ${ }^{3}$

Magnitude of Rescue Burdens. Routine acute care and emergency care are expensive. The cost of delivering a newborn ranges from $\$ 9600$ for a vaginal delivery to more than $\$ 21000$ for a cesarean delivery with complications. ${ }^{4} \mathrm{The}$ average cost for an appendectomy is $\$ 15850 .{ }^{5}$ Unless uninsured individuals pay out of pocket or incur debt, these expenses are passed on to hospitals, clinics, physicians, insured individuals, and taxpayers. In the aggregate, uncompensated care poses an enormous financial burden, totaling an estimated $\$ 56$ billion in 2008. ${ }^{2}$

Costs and Burdens to Potential Rescuees. For some, purchasing health insurance would force them to forgo essentials. Others can afford coverage without real hardship. For

Author Affiliations: Department of Bioethics, NIH Clinical Center, Bethesda, Mary land (Drs Rulli and Wendler); and Office of Vice Provost and Department of Medical Ethics and Health Policy, University of Pennsylvania, Philadelphia (Dr Emanuel). Corresponding Author: David Wendler, PhD, Department of Bioethics, NIH Clinical Center, Bethesda, MD 20892 (dwendler@nih.gov). 
example, $10 \%$ of uninsured individuals earn more than $400 \%$ of the federal poverty level. ${ }^{6}$ Proposed government subsidies further expand the population of those who can afford health insurance.

\section{Enforceability}

Not all moral duties are legally enforceable. However, the state can require individuals to fulfill their duties to not pose substantial burdens on others. Residents may be required to evacuate a hurricane zone for their own safety and for the safety of would-be rescuers. ${ }^{7}$ In North Carolina, individuals can be held liable for the costs of failure to evacuate. ${ }^{8}$ Similarly, an individual's obligation to not pose serious burdens on rescuers suggests an enforceable duty to buy health insurance.

\section{Waiving the Right to Care}

An individual's beliefs and convictions may result in a person refusing recommended care. For instance, it is important to respect Jehovah's Witnesses' refusal of blood transfusions. Does it follow that individuals should be permitted to waive their right to health care, rather than being required to purchase health insurance to cover the costs of emergency and acute care?

Even if individuals can waive their right to health care, it does not follow that physicians may decline to rescue them. If a motorcyclist who has waived the right to health care is involved in a crash, physicians should not stand by and allow the individual to bleed to death. A physician's duty to provide acute and emergency care is not grounded solely in individuals' right to be rescued; it is a requirement of benevolence and compassion at the core of medicine.

Declining to force a blood transfusion on an objecting Jehovah's Witness respects that individual's autonomous choices and values. In contrast, allowing motorcyclists who desire assistance to die simply because they failed to buy health insurance is morally unacceptable.

\section{Limits on the Duty to Buy Health Insurance}

Individuals' duty to reduce the burdens of rescue is not limitless. In the health care context, it requires only that they buy enough insurance to cover the costs of the care that physicians have a duty to provide. This argument does not imply that individuals have a duty to buy the level of insurance mandated by the ACA (although it may be compatible with other arguments for more expansive coverage). Instead, the present argument implies individuals have a moral duty to buy enough health insurance to cover the costs of acute care and emergency care. Once an individual has bought this level of insurance, that individual's duty to re- duce the burdens of rescue has been satisfied. Hence, that individual does not also have to eat broccoli or buy a gym membership.

\section{Conclusions}

Physicians and hospitals have a moral duty to provide acute care and emergency care to those who need it. The burdens of providing such care to the uninsured are very high, while the cost of purchasing insurance to cover these costs is not excessive for many. It follows that individuals have an enforceable moral duty to buy sufficient health insurance to cover the costs of acute care and emergency care. This moral duty provides grounds for an enforceable legal duty because the state has an interest in limiting individuals' imposition of substantial burdens on others. Although the Supreme Court will decide the constitutionality of the ACA insurance mandate, this analysis suggests that requiring individuals to buy health insurance is consistent with respect for individual liberty because individuals have a duty to mitigate the burdens of rescue they pose on others.

Conflict of Interest Disclosures: The authors have completed and submitted the ICMJE Form for Disclosure of Potential Conflicts of Interest and none were reported. Dr Emanuel reported receiving payment for speaking engagements unrelated to this work.

Funding/Support: This work was completed as part of the authors' official duties as employees of the US National Institutes of Health (NIH) Clinical Center.

Role of the Sponsor: The NIH had no role in the preparation, review, or approval of the manuscript.

Disclaimer: The opinions expressed are the authors' own. They do not represent the position or policy of the NIH, the US Public Health Service, or the Department of Health and Human Services.

Additional Contributions: Thanks to the faculty and fellows at the NIH Clinical Center, Department of Bioethics, for their helpful feedback on an early draft of the manuscript. Special thanks to Justin Lowenthal, BS, and Joe Millum, PhD, for their comments. These individuals did not receive compensation in association with their contributions to this article.

\section{REFERENCES}

1. Mariner WK, Annas GJ, Glantz LH. Can Congress make you buy broccoli? N Engl J Med. 2011;364(3):201-203.

2. Hadley J, Holahan J, Coughlin T, Miller D. Covering the uninsured in 2008. Health Aff (Millwood). 2008;27(5):w399-w415

3. Nicholson JL, Collins SR, Mahato B, et al. The Commonwealth Fund, issue brief: rite of passage? why young adults become uninsured and how new policies can help. 2009;64(Aug):1-20. http://www.commonwealthfund.org/ /media/Files /Publications/Issue\%20Brief/2009/Aug/1310_Nicholson_rite_of_passage_2009 .pdf. Accessed March 10, 2012

4. US Agency for Healthcare Research and Quality. Welcome to H CUPnet, healthcare cost and utilization project. http://hcupnet.ahrq.gov/. Accessed March 30, 2012.

5. Health Care Fees. Appendectomy prices. http://www.healthcarefees.com /inpatientSurgery/appendectomy.php. Accessed March 10, 2012.

6. Kaiser Commission on Key Facts. Medicaid and the uninsured: five basic facts on the uninsured, September 2009. http://www.kff.org/uninsured/upload/7806-02 .pdf. Accessed June 1, 2012.

7. Fairchild $\mathrm{AL}$, Colgrove J, Jones $M M$. The challenge of mandatory evacuation: providing for and deciding for. Health Aff (Millwood). 2006;25(4):958-967.

8. North Carolina General Assembly. North Carolina General Statutes, sec 166A.15.1 (2006): Civil Liability of Persons Who Willfully Ignore a Warning in a Disaster. http://www.ncga.state.nc.us/enactedlegislation/statutes/html/bychapter /chapter_166a.html. 